\title{
Cinética estrutural na esquizofrenia
}

\author{
Melissa Garcia Tamelini ${ }^{1}$
}

\begin{abstract}
Resumo
O presente artigo discorre a respeito da mobilidade da estrutura psíquica, especificamente na esquizofrenia. Inicialmente, parte de uma breve revisão das categorias de entendimento dessa patologia dentro da tradição da Psicopatologia Fenômeno-Estrutural. A seguir, faz algumas considerações a respeito do campo endógeno, correlacionando-o com os conceitos apresentados. E, por fim, o artigo foca na questão da cinética estrutural, diferenciando tipos ideais de movimentação e suas possíveis implicações prognósticas e terapêuticas.

Palavras-chave: Psicopatologia Fenômeno-Estrutural; Mobilidade Estrutural; Esquizofrenia.
\end{abstract}

\section{Structural Kinesis in Schizophrenia}

\begin{abstract}
The present paper discourses about the possibilities of structural mobility, especially on the schizophrenia. First, it sets forth a briefly review of the fundamental categories for understanding this pathology inside the Phenomenostructural Psychopathology. Then, the author makes some considerations about the endogenous field and the shown concepts. Finally, the article focuses on the structural kinesis, discerning ideal types of structural movement, with some therapeutic and prognostic implications.
\end{abstract}

Key-words: Phenomeno-structural Psychopathology; Structural Kinesis; Schizophrenia.

1 Médica Psiquiatra. Membro da Sociedade Brasileira de Psicopatologia Fenômeno-Estrutural. Médica Assistente do Instituto de Psiquiatria do Hospital das Clínicas da Faculdade de Medicina da USP. Email: melissa@fenomenoestrutural.com.br 


\section{Ponto de Partida}

A esquizofrenia sempre foi protagonista no campo de reflexões da Psicopatologia. Apesar da irrevogável importância de obras dedicadas à questão, especialmente aquelas de autores como Binswanger e Minkowski, não parece hiperbólico afirmar que permanecem abertas inúmeras possibilidades de investigação psicopatológica. A contemporaneidade não tomou para si a responsabilidade de dar seguimento às perspectivas abertas pela tradição. Pelo contrário, mais inclinada a perseguir ambições de causalidade, distancia-se da clínica e satisfaz-se com resultados superficiais.

Festejando o surgimento de uma revista que intenta justamente prestigiar e promover a Psicopatologia Fenômeno-Estrutural e, simultaneamente e de modo não menos importante, prosseguir, através da abertura de novos caminhos, o presente artigo elege alguns ângulos para a contemplação da esquizofrenia. Mais especificamente, irá pensar a mobilidade estrutural nesta patologia.

A inspiração para as colocações seguintes derivam do contato continuado com pacientes esquizofrênicos. Não haveria de ser outra a fonte em um trabalho de filiação fenomenológica. À clínica também cabe o privilégio de balizar as formulações propostas, uma vez que essas, para serem relevantes, devem submeter-se ao seu crivo.

\section{Plano de voo}

Inicialmente, algumas considerações serão feitas a respeito dos alicerces fundamentais para o entendimento da esquizofrenia pela Psicopatologia Fenômeno-Estrutural. A literatura clássica é magistral na redução da miríade de manifestações esquizofrênicas a uma estrutura psíquica, por sua vez "condição de possibilidade" para a ocorrência de fenômenos como delírios e alucinações. Tal estrutura será dissecada em suas categorias fundamentais, temporalidade e espacialidade. Mais do que uma rigorosa compilação, prioridade será dada à identificação de pontos cruciais, premissa e reparo, para a exploração subsequente. 
A seguir, o "desenho estrutural" da esquizofrenia, uma vez apresentado, será projetado em perspectiva longitudinal. Tanto de forma retroativa como prospectiva, ou seja, desde as manobras necessárias para a formatação da estrutura tal como é conhecida enquanto patologia até suas possibilidades futuras. Adentrase, assim, no complexo campo das movimentações psíquicas, indispensável para a discriminação de formas clínicas, modalidades de evolução e decisões terapêuticas.

A grande questão, de antemão antecipada, está posta: em que medida a estrutura psicótica, que prima pela paralisação, contém possibilidades genuínas de movimentação? Ou ainda, quais são os tipos e finalidades dos movimentos estruturais? Mais, ao que se atribui a titularidade desses?

Por fim, alguns esboços sobre a composição entre mobilidade estrutural na esquizofrenia e suas possíveis implicações no âmbito terapêutico.

\section{A Estrutura Esquizofrênica}

O enfoque fenomenológico prioriza situar o acontecer fundamental da patologia, manancial de sua ampla variedade fenomênica. A Psicopatologia Fenômeno-Estrutural não legitima a composição simplista, subsidiária da nosologia atual, que entende a patologia como uma mera reunião de sintomas independentes, agrupados em intervalo de tempo típico.

Ao apartar-se deste loteamento arbitrário em funções emancipadas, a consciência enquanto totalidade é o único cenário possível, como já explicita Minkowski (2005). Entretanto, não se trata de um todo formado pela simples coletânea das partes, mas de uma "estrutura hierarquizada, uma articulação orgânica entre diversos níveis e estratos" (Messas, 2004, p. 86), que tem na sua base três elementos fundamentais: tempo, espaço e contato vital com a realidade.

Deve-se ressaltar que operar com a noção de estrutura não exime da preocupação cinética, ainda que tal possibilidade, vital para a higidez psíquica, esteja justamente posta em xeque na patologia (Messas, 2010). Uma proposta de tipos de movimentação estrutural, particularmente na esquizofrenia, será feita na proposição subsequente.

A estrutura vivida é um construto crucial para a investigação psicopatológica. Seu reconhecimento implica outorgar a prioridade aos seus 
fundamentos ontológicos, sem os quais qualquer ordenamento e descrição das manifestações mentais estão fadados à inespecificidade. A esquizofrenia, como paradigma aqui escolhido para o patológico, passa a ser reconhecida como um tipo específico de adulterações do "vivido", e não simplesmente do vivenciado, "somente acessível a um diagnóstico intuitivo e não semiológico" (Tatossian, 2006, p. 64).

A psicose converte-se, assim, em objeto do psicopatologista, por excelência, nas coordenadas temporoespaciais. Não há, todavia, incompatibilidade com o postulado endógeno. Ainda que mais debatido na mania e melancolia, ele é tão importante quanto na esquizofrenia. Tatossian enfatiza que "a esquizofrenia, com efeito, é também "experimentação da natureza" e as "irrupções elementares" da derrelição ocupam aí um lugar subestimado por Binswanger - em particular nas esquizofrenias deficitárias, que, elas também, são "aquelas de todo mundo"'"(Tatossian, 2006, p. 325).

Posteriormente caberá discorrer, ainda que de forma sucinta, a respeito do ponto de contato entre estrutura e natureza endógena e, por ora, situaremos a questão como foi colocada por Messas:

Separar temporariamente - em nome da didática - a natureza endógena de todo o restante do psiquismo não significa, no entanto incompatibilizá-la com este. Pelo contrário, acarreta uma adicional complexidade ao já arcano universo mental: funda-se assim o campo de investigação das relações natureza-estrutura. A estrutura, como um feixe de coordenadas temporoespaciais dando as condições de existência da mente consciente, tem de lidar com uma pressão desde dentro a forçar seus limites formais ora para um lado ora para outro. (Messas, 2010, p. 97)

Independentemente de qualquer formulação causal, são as composições de âmbito estrutural, não apenas a temporalidade e a espacialidade, mas também a articulação entre elas, sua "roupagem material" entre outras, que contribuirão majoritariamente para o esclarecimento psicopatológico. Reconhecer as características fundamentais da estrutura esquizofrênica, embora não "esgote" o caso clínico (exceção feita a "aquelas de todo mundo"), é imprescindível, inclusive dentro da perspectiva histórico-biográfica.

A temporalidade é a coordenada que desfruta de maior prestígio na seara fenomenológica. O tempo vivido, composto de instâncias articuladas, qualitativamente diversas entre si, é, por natureza, "irradiação", transcendência do 
passado em direção ao futuro. As três "estases", passado, presente e futuro, não são homogêneas e sustentam papéis distintos. O passado, por exemplo, é zona de estabilidade, da sedimentação vivencial. É fundamental como patrimônio, ponto de partida e apoio para os desdobramentos expansivos do futuro. O presente é o plano da ação imediata, das articulações com o mundo perceptual e corpóreo. $\mathrm{O}$ futuro, por sua vez, é a zona de projeção da consciência, do inabdicável prosseguir adiante. A capacidade de temporalizar-se confunde-se com o próprio projeto humano e é justamente o devir que congrega os elementos mais nobres da existência, como o impulso ético (Minkowski, 2005). É possibilidade e virtualidade, subsídio para a expansão e, ao mesmo tempo, uma espécie de "norte" na bússola do percurso individual.

As distintas formas de alteração da temporalidade constituem o paradigma da doença mental, que na sua acepção mais forte é sinônimo de inviabilização da transcendência humana. Pode haver a quase extinção da possibilidade de futuro ou ainda a desproporção de uma das categorias em relação às demais. A patologia mental, brotando de um substrato endógeno favorável, expressa-se pelo congelamento da temporalidade e pela incapacidade no cumprimento do "destino" da existência.

Na esquizofrenia, a impotência para o avanço adiante e a desarticulação das instâncias temporais deixam a consciência ilhada em um presente não autêntico, fadado a esgotar-se em si mesmo. Minkowski (2000) frisa as consequências decorrentes da alteração do "contato vital com a realidade" e da obstrução do futuro, como, entre outros, os atos em "curto-circuito" e o geometrismo mórbido. O colapso na genuína temporalização, para Binswanger, constitui-se a partir do fracasso no "encontro dual" e no "amor" (categorias ontológicas do ser) e é responsável pela "materialização" (Caso Ellen West) ou "mundanização" (Caso Jurg Züntd) da existência (Binswanger, 1968).

A espacialidade, por sua vez, também é de fundamental importância no entendimento da esquizofrenia. Desde o prejuízo na amplitude e distância vividas até a geometrização do pensamento, quebra das fronteiras do eu, diversas são as alterações descritas. A diminuição da "distância vivida" culmina com uma conglomeração espacial; com o comprometimento da amplitude vital, há a substituição da casualidade, coincidência e acaso por um mundo hiper-significado, hostil, repleto de causalidade e determinações (Minkowski, 2005). Pode haver certa "promiscuidade" entre as modalidades espaciais, como visto no acavalamento do "espaço escuro" sobre o "espaço claro" ("público"), responsável pela cessão de conteúdos da intimidade à esfera da socialização e substrato das vivências 
alucinatórias e delirantes (Minkowski, 2005), ou ainda modificação da essência de cada uma das distintas categorias. A espacialidade também pode ser considerada em relação à preponderância do vetor de afastamento do mundo em detrimento de mecanismos de aproximação, assim como através da sua "consistência" fundamental, como, por exemplo, ora se comportando como dura imposição, resistência, ora como fluidez etérea.

Desta maneira, a forma clínica que conhecemos por esquizofrenia é a manifestação fenomênica de uma derrocada estrutural, seja completa e irredutível, seja em variantes parciais e menos severas. Esta decadência é sintetizada pela impossibilidade de uma temporalização autêntica e pelas distorções espaciais e no contato interpessoal. $\mathrm{O}$ retrato falado das formas que adjetivam a esquizofrenia, como paranoide, hebefrênica, catatônica ou simples, refere-se a possíveis combinações destas alterações fundamentais, assim como a persistência do processo em determinado âmbito estrutural, o que naturalmente implica gravidade.

A estrutura esquizofrênica, nos moldes de uma configuração típica e deformada, pode conduzir à premissa, como já foi dito, de que a mobilidade não seja tema aqui. Ao evitar este equívoco, abre-se uma enorme clareira. A questão do movimento já havia sido posta de alguma maneira nos magistrais casos de Binswanger (1957), agrupados sob o titulo de "Esquizofrenia". Neles, entretanto, o desdobramento estrutural, é visto mais em sua vertente "negativa", uma espécie de história de um colapso, fazendo jus à concepção jasperiana de processo psíquico. Como o estreitamento existencial progressivo não parece ser a única via de movimento na esquizofrenia, faz-se imperativo investigar outras possibilidades. Desde a negociação feita entre a natureza endógena e a estrutura, com maior ou menor participação do contexto histórico, até as tentativas de restabelecimento estrutural e de genuína transformação, várias são as articulações cinéticas possíveis. Buscar conhecê-las é essencial para o aprofundamento psicopatológico e elucidação de temas relativos ao prognóstico e à terapêutica.

\section{Considerações sobre o Movimento Estrutural na Esquizofrenia}

O conceito de estrutura comporta simultaneamente o paradigma de estabilidade e de movimentação. A consciência projeta-se adiante e o desdobrar da forma pode culminar com a transformação. 
A patologia, apogeu da imutabilidade, é um desafio à mera factibilidade da mudança. No melhor cenário, a movimentação estrutural estará confinada à novas imposições. Messas (2010), no livro "Ensaio sobre a Estrutura Vivida", que trata de forma aplicada questões inerentes à mobilidade estrutural, assim coloca:

Na doença mental, a estrutura tem uma capacidade elástica inferior àquela observada nas estruturas individuais. A estrutura patológica permanece idêntica a si mesmo ao longo do tempo (nota: fica claro que ela pode desaparecer com a melhora clínica ou dominar o todo da personalidade; neste caso a dominação se dá pela redução relativa da participação global das zonas saudáveis na totalidade mental, ou seja, o estiolamento da personalidade faz com que ela seja invadida pela patologia). (p. 107)

Os múltiplos vetores de mobilidade podem ser analisados sob a forma de tipos ideais: as perspectivas de futuro da "estrutura esquizofrênica", passando desde a mera distração promovida por uma "troca" de fenômenos, que compartilham o mesmo nível hierárquico e não constituem uma autêntica saída de posição, até os movimentos mais "promissores", que ousarão desafiar o status quo da psicose.

Antes de intervir propriamente no campo da transformação, é necessário um ligeiro recuo para contemplar que tipo de força é determinante na formação da marca temporoespacial esquizofrênica. É hora de colocar em pauta a ação endógena. Logo a seguir, uma nova instância será posta em diálogo com estrutura e natureza.

\section{A - A Atuação Endógena}

Por endógeno, entende-se o campo de influência do Endon, regente das leis naturais do humano, responsável pelos ritmos e pelo movimento (Tellenbach, 1975). Tal presença pode se valer de mecanismos biológicos, mas é anterior a este campo (metabiológico e metapsicológico).

A clínica das patologias ditas endógenas nada mais é do que a consequência fenomênica do tipo capital de desintegração temporoespacial. A ação da natureza pode variar na constância, localidade e intensidade. Deste modo, a esquizofrenia, 
tal como foi apresentada previamente, é a resultante final do efeito endógeno sobre a estrutura, culminando com uma desarticulação característica.

O triunfo da natureza explicita-se pelo domínio de suas regras e pela geração de formas estruturais mais homogêneas e niveladas. Neste momento, prosperam mecanismos e leis de causalidade, escasseando-se sensivelmente o poderio e o exercício da livre decisão.

Assim, ao situar a Esquizofrenia dentro dos desígnios do endógeno, adiciona-se uma nova categoria, inclusive, mas não exclusivamente, de âmbito causal. Esta força alterna períodos de extrema visibilidade com outros de presença deuteragonista, sendo a irrupção da patologia (broto) e os episódios de exacerbação (surtos), paradigmas de grande diligência endógena.

A natureza pode se valer "oportunisticamente" de um momento de maior fragilidade (estrutural ou histórica) ou se fazer soberana independentemente de qualquer pretexto biográfico. Nessse caso, a eclosão da patologia torna-se uma fatalidade, uma espécie de prova cabal da potência endógena, a mais autônoma possível em relação à camada vivencial.

É certo que quanto mais premente a determinação endógena, maior a restrição à autonomia de outras instâncias (como expressão máxima, podemos citar o engessamento estrutural, típico das formas deficitárias, "aquelas de todo mundo"). A atuação tirana da natureza tende a tornar a estrutura um mero joguete, ao impor as formas típicas da doença, e a esgotar a liberdade individual. A este respeito, Straus afirma: "A psicose na verdade metamorfoseia o homem em sua natureza de criatura... não lhe deixa nenhuma possibilidade de se comportar de outra maneira nem de decidir de outra forma" (Tatossian, 2006, p. 316).

No geral, são a própria estrutura, as amarras históricas e o projeto individual que funcionam como pontos de contenção endógena (esquizofrênica). Uma vez que esses elementos estejam menos sólidos, abre-se uma janela de oportunidades à patologia. Fatores de risco, assim, podem ser construídos a partir do contexto estrutural ou vivencial, mas sempre dependem de um alinhamento sinérgico com a natureza para a formação deste pré-campo.

A adolescência, típico período de eclosão da esquizofrenia, é paradigmática quanto à vulnerabilidade. A estrutura em franca expansão, pressionada pela força endógena de amadurecimento, abre um flanco e, nesta espécie de "troca de guarda", o terreno torna-se fértil às expressões indesejáveis do endógeno. 
Os momentos de transformação como um todo exigem máxima atenção, justamente pelo descobrimento das proteções naturais da estrutura. Não apenas aqueles determinados "desde dentro", como as fases de maturação, mas também aqueles oriundos de fora. A camada vivencial também traciona a estrutura e as "crises" (no sentido da modalidade histórico vital de Karl Jaspers) podem se constituir um convite à participação endógena.

A "situação", descrita por Tellenbach como essencial no pré-campo melancólico, é um construto intermediário entre as duas posições anteriores (Tellenbach, 1975). "A situação é sempre uma relação original entre pessoa e mundo, não como fator estático, mas como "operação" constante do ser no mundo, tão constante como a espacialização e a temporalização" (Tatossian, 2006, p. 182). A composição estrutural típica ("typus melancholicus"), que carrega a impressão digital do endógeno em questão, viabiliza, no âmbito vivencial, a formação da situação específica, um dilema para si mesma, determinante para o "sucesso" do projeto melancólico.

O binômio esquizoidia-esquizofrenia parece não obedecer a lógica tão estável quanto a do "typus melancholicus"-melancolia, mas o arranjo temporoespacial típico da esquizoidia também gera suas "situações" de risco à higidez psíquica, tanto histórico-vivenciais como exógenas.

No caso exógeno, o exercício continuado de uma intoxicação, como a de canabinóides, pode levar à vulnerabilidade estrutural (mais acentuada nos esquizóides?). O vetor de forças gerado pela contínua presença da substância pode lesar o arcabouço estrutural, promovendo a dissolução de pontos de amarra com o mundo. A consciência mais distanciada do real, leve e esvaziada, pode ser terreno fértil a um latente núcleo endógeno. E, como mostra de como as categorias de fragilidade se interpõem complexamente no real, a própria natureza pode estar implicada na predileção pelo estilo de intoxicação. Assim, as forças em jogo, natureza, estrutura e mundo vivencial, mais constituem um mosaico, com determinantes sobrepostos e interdependentes no sucesso da patologia.

A preponderância endógena é também a marca dos surtos, aqui com um agravante em cena. Em razão do ocorrido prévio, um novo feito endógeno pode encontrar menor resistência estrutural, consolidando o domínio do patológico, aumentando sua abrangência ou calcificando a estrutura em formas cada vez mais impessoais. A cada nova aparição do exército endógeno, as alterações estruturais tendem a ser mais graves, assim como a evolução da patologia, e os indivíduos mais próximos dos "experimentos da natureza" ficam, dissolvendo drasticamente 
as particularidades e as vicissitudes da existência. A camada vivencial, como anteriormente dito, pode estar mais ou menos implicada neste re-agenciamento.

As diferenças nas evoluções típicas entre a esquizofrenia e a melancolia e mania podem também remeter ao campo do endógeno. Ao contrastar a evolução processual da primeira com a evolução em fases das demais, podemos depreender estilos de atuação endógena distintos. Na melancolia e na mania, a expressão endógena alicia integralmente a estrutura, produzindo configurações clínicas mais previsíveis. Assim, na vigência da fase, há um estrangulamento das particularidades biográficas, ainda que, em geral, a experiência de Eu mantenha-se íntegra. Ao mesmo tempo, guardam a enorme vantagem da reversibilidade. $\mathrm{O}$ poder de fogo da farmacologia na mania e melancolia deve-se à possibilidade intrínseca de restituição temporoespacial, ainda que a terapêutica pouco possa contra a natureza enquanto potencialidade.

As esquizofrenias, por outro lado, seriam mais "biográficas". A historicidade, especialmente nas formas paranoides, pode se manter preservada. Em contrapartida, o endógeno desenha contornos mais estáveis e permanentes e a reversão torna-se a grande problemática, sendo mais raros os casos de restituição "ad integrum". Não seria exagero afirmar que mesmo a ocorrência de apenas um único "surto" pode deformar a estrutura definitivamente, ainda a abrangência de que tais marcas variem entre evidentes formações até "fibroses" microscópicas.

Do ponto de vista clínico, toda "entrada em cena" do endógeno gera uma "des-acomodação" estrutural e as formas psicopatológicas tendem a ser mais instáveis e plurifacetadas. Em um cenário de supremacia absoluta da natureza, após o momento inicial, a estrutura tende a ficar imóvel, congelada sob a forma da patologia. Entretanto, outras possibilidades do ponto de vista da estrutura são admitidas. Desde o momento inicial do recrutamento endógeno até as tentativas posteriores de restabelecimento dos propósitos estruturais, distintas articulações podem ser identificadas, sob a ótica estrutural.

\section{B- Movimento e Estrutura}

A natureza pode ser considerada o grande manancial de movimento como um todo: a força de manutenção e expansão vitais tem como nascedouro, em última instância, a matéria. Só há razão de se conceber outro domínio se for possível delimitar diferenças e conceder alguma autonomia em relação ao anterior. 
Mas, vale a advertência, ainda que se postule outros campos, estes sempre serão instâncias encarnadas.

Natureza e estrutura já foram devidamente apresentadas. A primeira, como elemento de regência dos ciclos, dos ritmos, pode conter distintas potências e agenciar a estrutura para a execução de finalidades diversas (nem toda possibilidade da natureza está explicitada estruturalmente). A natureza pode se comportar como potência silenciosa, "escondida" por sob um arranjo estrutural "neutro" ou destoante, e ser surpreendente, como, por exemplo, na deflagração de um quadro esquizofrênico em um estrutura hipertímica. Ou ainda, ser "previsível", como no caso da melancolia no typus melancholicus, cujos riscos endógenos podem ser antecipados a partir da leitura estrutural.

A estrutura, por sua vez, é a viabilização formal para todas as determinações presentes na consciência. Além de si mesma e da natureza, ela também veicula expressões provindas de outro recôndito. Em jogo na consciência, há um "eu livre". Desta porção nobre e grandiosa, na melhor acepção do humano, nasceria a capacidade de se auto determinar, de imprimir, através da verdadeira decisão, um rumo distinto aos caminhos da existência. Como para tal exercício, novamente, a estrutura é o subsídio formal, os direcionamentos da livre decisão podem, através de vetor de tração, inspirar uma vulnerabilidade à patologia.

Com todas as instâncias postuladas, torna-se relevante pensar a articulação e a proporção delas na consciência (Blankenburg, 1982). De um lado, estaria a composição harmônica entre as partes, cujo regente maior seria o "eu livre", aliciador dos elementos necessários para a "melhor" condução da existência em uma atuação menos limitada pela natureza. No pólo oposto, na patologia, a força de impressão biológica no psiquismo pode comprimir a autonomia da estrutura e até acabar na supressão da possibilidade de atos genuinamente livres. Binswanger assinala que as formas iniciais da esquizofrenia ainda podem comportar sua manutenção: "O poder da liberdade chega ainda a se manifestar na forma insidiosa da esquizofrenia", (Binswanger, 1968, p. 372). Em contextos mais graves, entretanto, a liberdade converte-se em "coação e calamidade" e a alteração da soberania da existência pode ser vista pela "coagulação do eu livre em objeto, tipo coisa, cada vez menos livre e mais dependente" (Binswanger, 1968, p. 425). No célebre caso Ellen West, a questão está problematizada no suicídio, que se justifica simultaneamente pelo destino e pela escolha (e mesmo na escolha, ela é feita segundo o desfrute, uma modalidade estrutural). 
A estrutura, como foi visto, ocupa esta posição intermediária, subsidiando as possibilidades tanto da natureza como do "eu livre". É uma forma em movimento, espécie de "estabilidade instável", o que significa balizar a coexistência harmônica de duas tendências opostas e, mais ainda, fundamentais, estabilidade e movimento (Messas, 2010). Ela movimenta-se integralmente, permitindo a emergência de novas formas e novos conteúdos à consciência. A transformação traduz-se em suas coordenadas essenciais sob a forma de uma temporalização autêntica e manutenção de um "espaço grávido de possibilidades individuais" (Minkowski, 2005, p. 378).

Ao separar uma cinética de titularidade endógena de outras, tentamos discriminar estilos de ocorrência e consequentes implicações. A mobilidade dada por ordenação endógena é ditatorial e aguda, imposição de uma nova articulação não anunciada, uma .(de)forma universal, reconhecida enquanto síndrome psicopatológica. A plenitude da patologia reflete o triunfo de uma forma "perfeita", sem desequilíbrios, sentença definitiva à consciência. Tal dominação pode ser tamanha a ponto de tornar fictícia a possibilidade da autodeterminação.

O movimento de origem estrutural, diferentemente, tende a ser ordenado, progressivo, um tornar-se a si mesmo a partir do que se é e se foi. A estrutura testa novas possibilidades, que emergem a partir das anteriores, em um contínuo desdobramento. O resultado desta sucessão de desequilíbrios ordenados, que tendem a um fim (eventualmente a viabilidade dos projetos provindos do "eu livre"), chama-se crescimento. Esta expansão busca a "forma ideal", que, diferentemente da patologia, confunde-se com o apogeu, e não declínio. A forma "perfeita" da estrutura pressupõe o encontro da melhor configuração essencial, aquela que diminui ao máximo qualquer imposição ao exercício da liberdade. Leva em conta a composição de todos os fatores implicados, valendo-se inclusive do melhor da natureza a serviço do homem, que se torna a "causa de si mesmo".

A mobilidade estrutural visa a duas finalidades: inauguração de uma nova possibilidade ou manutenção da forma. O primeiro tipo, variante mais nobre, joga a consciência adiante, em cumprimento ao seu destino expansionista. O segundo move no sentido "lateral" e pode significar troca de fenômenos, mas não de fato expansão. Este é mais corriqueiro, ainda que essencial à estrutura, revestidas de especial importância na patologia, na medida em que busca encontrar alguma estabilidade provisória, pressuposto inclusive da movimentação integral. $\mathrm{Na}$ esquizofrenia, ambos conduzem a diferentes perspectivas e serão analisados a seguir. 


\section{"Acomodação" estrutural}

Como vimos, a avalanche endógena modifica profundamente a estrutura, privilegiando as formas típicas da natureza psicótica. Em um primeiro momento, pode significar intensa desarticulação da unidade estrutural e até mesmo dificuldades no reconhecimento de uma estrutura como tal. A pressão endógena avassaladora atua no sentido do ditado da forma estrutural e do aprisionamento do "eu livre". São períodos de grande volume de sintomas, nos quais a mente fica tomada por mecanismos patológicos. Há a radical dissolução do estilo habitual da consciência, com abalo na significação, quebra das fronteiras espaciais até aniquilação da própria experiência de eu (por exemplo, em quadros severos de catatonia ou hebefrenia).

Tais manifestações podem predominar continuamente, constituindo-se nestes casos uma oportunidade para a contemplação da natureza psicótica em todas as suas cores. Entretanto, como regra geral, a evolução dos pacientes esquizofrênicos mostra que, mesmo sem tratamento apropriado, ocorre atenuação ou modificação das apresentações clínicas das fases agudas. A natureza não tende a ser uma força que atua ininterruptamente nestes moldes e, a partir da diminuição do protagonismo endógeno, há a busca de restabelecimento formal, uma espécie de "acomodação estrutural".

Essa primeira medida é fundamental para a reaquisição de alguma estabilidade dentro do "estado de sítio endógeno" e, em um cenário otimista, para a retomada futura dos propósitos expansionistas da consciência. A fratura no psiquismo, assim como no caso ortopédico, demanda uma imobilização, no intuito de condensar-se. A consolidação desta nova forma coloca em cena expressões fenomênicas mais duradouras, mas que não alteram o predicado psicótico da estrutura. Ou seja, a acomodação estrutural é o reflexo de um "acidente fenomenológico", de um grave deslocamento temporoespacial, mas é o primeiro passo para a restituição de uma totalidade articulada na consciência.

A acomodação estrutural traz possibilidades distintas. Se, por um lado, a estabilidade readquirida é imprescindível para a execução de um movimento coordenado, por outro, pode agravar o prognóstico. A "condenação" se dá justamente pela emergência de uma configuração por vezes demasiadamente sólida e inelástica. Assim, ao coagular as formas temporoespaciais da natureza, a 
estrutura lança mão de uma solução de compromisso: volta a ser reconhecida enquanto forma habitual, mas pode acabar por se imobilizar demasiadamente. Esse engessamento, que suspende provisoriamente as pretensões cinéticas, pode, por outro lado, "financiar" a sua ocorrência futura. Às características temporoespaciais desta fase de acomodação, correspondem as formas fenomênicas mais duradouras da clínica. Tipicamente há a permanência atenuada ou automatizada de mecanismos psicóticos, próprios do autismo esquizofrênico.

Uma das formas de adquirir estabilidade estrutural seria a redução do perímetro vivencial. A consciência aproxima o horizonte vivencial, limitando o rol de possibilidades. Passa a operar em um território mais indiferenciado, menos complexo e de ambições diminutas, mas salvaguardando a experiência de "eu" (que, como dito, pode sucumbir à força continuada da natureza). Esboça com esta tentativa uma retomada de alguma autonomia estrutural, em meio ao apogeu endógeno. A fragmentação espacial do eu tende a diminuir e alguns contornos são desenhados através da vedação, mesmo que parcial, da solução de continuidade eu-mundo. É um período de maior familiaridade com a realidade, à medida que os significados se assentam. A aproximação do horizonte vivencial também favorece uma melhor articulação temporal, que pode ser vista no ressurgimento de alguns hábitos ou mesmo na melhora do pragmatismo. $\mathrm{O}$ encolhimento, então, restitui a possibilidade da estrutura se constituir como tal e promove coesão: "A estrutura só pode expandir-se em sua totalidade, jamais em fragmentos" (Messas, 2010, p. 115).

A formação de um núcleo delirante também pode operar na estabilização, uma espécie de coágulo à estrutura que desfalece. A provisão de uma significação rígida estabiliza a consciência no mundo e, quanto maior a materialidade deste tampão, maior será a dificuldade de remoção. A esquizofrenia, especialmente na apresentação paranoide, pode cursar com a manutenção de um cerne delirante definitivo, que cresce ou reduz sua abrangência, mas que se sustenta continuamente, certamente um ônus ao "eu livre". A respeito da função restauradora do delírio, função essa que pode ser extrapolada para todas as tentativas de acomodação estrutural, Charbonneau afirma: "Le délire est exclamation de catastrophe e sa tentative de réparation. C'est à la fois le naufrage et les tentatives de colmatage et d'évacuation du navire, plus ou moins cohérentes ou ébauches selon l'importance des affectations ipséiques originaires. Ce peut être aussi le naufrage dans la têmpete des navires de secours" (Charbonneau, 2010, p. 96).

Uma outra maneira de acomodação é a emergência da corporeidade a uma posição de destaque. Em um cenário de fragilidade do eu, a corporeidade, pelo seu 
caráter de materialidade e resistência, facilita a ancoragem e promove estabilização: "a perplexidade esquizofrênica determina a paralisia do corpo como instrumento de descoberta e articulação da consciência" (Tatossian, 2006, p 96). "A "mundaneidade do corpo" vivo aparece, assim, paradoxalmente na retração do mundo no corpo, único domínio em que uma ordem pode ainda ser buscada" (Tatossian, 2006, p. 100).

Todas as possibilidades descritas acomodam a estrutura dentro do novo contexto, mas, dependendo da magnitude de resposta, dificultam a mobilidade mais genuína. De qualquer forma, após esta fase, a estrutura pode começar a se movimentar, em vetores e finalidades diversas.

\section{"Pseudomovimento"}

O primeiro tipo de movimento é aquele que visa a manutenção da própria forma. "Trata-se de uma forma lateral de movimentação ou, mais tecnicamente, pseudomovimentação" (Messas, 2010, p. 84). A consciência não se expande o tempo todo. Distintamente, ela tende a manter a mesma configuração por longos períodos, ensaiando a ocorrência de modificações legítimas.

Como este tipo de mobilidade acentua o status formal vigente, pode significar, paradoxalmente, não a saída, mas o agravamento do atributo psicótico. Uma forma que se movimenta sobre si mesma, já sem a elasticidade suficiente para se projetar adiante, naturalmente se desgasta, espolia suas possibilidades em um percurso estéril, fadado a esgotar-se em si mesmo. Ainda que permaneçam zonas saudáveis "latentes", a estrutura pode estar toda angariada para a execução de pseudomovimentos.

Esta vertente conservadora de mobilidade tende a reforçar os mecanismos de acomodação e a contribuir para que eles se tornem mais onerosos neste segundo momento. A ausência de desequilíbrio na forma dominante consolida e amplifica sua abrangência, realçando a unidade temporoespacial alinhada com o endógeno, o que naturalmente está refletido na cronicidade esquizofrênica.

Esse "patinar" espoliador está bem exemplificado no caso Ellen West. Com a evolução do caso, o processo patológico conquista território e atinge recônditos estratégicos (no caso em questão, a tendência a ser etérea chega à zona corpórea), tornando irreversível a tendência de distanciamento de uma verdadeira expansão. 
Os "giros" no presente inautêntico, nos moldes das atitudes esquizofrênicas, como descritos por Minkowski dentro do "autismo rico", exemplificam este tipo de mobilidade que não está comprometida com a diferenciação e acaba por eliminar as autênticas possibilidades estruturais.

Como a estrutura esquizofrênica não mostra grande aptidão à expansão, a movimentação lateral pode persistir como modalidade dominante. Esse giro em falso estrutural leva a simples troca de fenômenos. Clinicamente, reflete-se no empobrecimento típico das apresentações deficitárias da esquizofrenia, que inspira grande parcimônia quanto às expectativas de evolução e, contra o qual, pouco se pode fazer no âmbito terapêutico.

Felizmente, a estrutura esquizofrênica também pode ensaiar movimentos expansivos, mesmo com o ônus da paralisação outrora necessária. Naturalmente, alguns riscos se anunciam, sendo o pior deles a abertura de uma nova janela de oportunidades à natureza. Ao relaxar a paralisante ancoragem rígida, pode haver diminuição da força de contenção vigente do endógeno, de cujo poder já não se duvida mais. Em relação ao verdadeiro ensaio de prospecção, surgem os fenômenos de "saída da psicose".

\section{Movimento expansivo}

Diversamente do tipo anterior, a mobilidade aqui está comprometida com o nascimento de uma nova forma.

A consciência como forma arquitetônica, o movimento como dilatações e condensações especiais desta forma, e a interpessoalidade magnética e genética das alterações desta forma, compõem a transformação. Movimento para além da forma; a transformação indaga constantemente a forma e sua superação. (Messas, 2004, p. 168)

Pode-se denominar de "saída" os fenômenos aliciados à ruptura das condições vigentes. No geral, são simultâneos ou secundários aos de acomodação e de manutenção, uma vez que o rearranjo formal, que se dá após o desmonte endógeno, é condição prévia para a emergência de projeções autênticas de crescimento. Estas formações podem derivar da retomada da vertente expansiva 
de fonte estrutural ou da persistência de zonas independentes dentro do psiquismo, que resistiram de certo modo imunes à devastação psicótica.

O contato interpessoal é a via régia na captura dos processos de transformação. Percute-se zonas mais saudáveis e a melodia proveniente do dueto paciente-psicopatologista torna-se mais instigante e complexa, divergente da monotonia e tédio das formas genuínas da natureza ou mesmo da fase de acomodação. Ainda que distante do verdadeiro encontro dual, desponta uma tendência de acréscimo na alocação de recursos na interpessoalidade. Há o recrudescimento de novas notas, com acréscimo da reciprocidade e diminuição da "anonimação" e "mediatização", típicas do encontro com o psicótico (Dörr, 1995).

A expansão psíquica transcorre através de um desequilíbrio promovido por uma nova forma, destoante da totalidade estrutural. Este abalo pressupõe a coexistência de tensões opostas, o novo e o vigente, que poderão compor uma nova possibilidade. Assim, de modo sintético, pode-se dizer que o movimento expansivo só ocorre a partir da retomada da vocação dialética da consciência.

A proporção dialética é chave para a tradição fenomenológica: a psicopatologia passa a ser vista não a partir de "destruições ou negatividades do ser humano", mas a partir das "rupturas do equilíbrio dialético (Blankenburg, 1982) entre as potencialidades que lhe são imanentes e que se autonomizam" (Tatossian, 2006, p. 317).

O desequilíbrio dialético entre possibilidades dadas à consciência pode ser analisado em vários planos. Desde a autonomização da natureza, esmagando as pretensões de estrutura e "eu livre", até a preponderância de alguma tendência dentro de cada uma destas instâncias. A retomada da mobilidade expansiva na esquizofrenia se dará através do recrudescimento da mecânica dialética, no âmbito espacial, temporal ou simultaneamente em ambos.

$\mathrm{Na}$ espacialidade, podemos citar o reaparecimento de um espaço íntimo, mais afeito às incertezas e dúvidas, consequência da vedação da fratura espacial. A retomada da intimidade acarreta a diminuição do raio delirante. Ainda que o núcleo delirante sobreviva em geral, pode coexistir ao lado de um halo de significações distintas, não comprometidas com a lógica psicótica. Esse "novo" espaço pode acolher os elementos que estavam desmesuradamente vividos no espaço público e também viabilizar o surgimento de elementos que só podem florescer nas condições aqui ofertadas. A intimidade é fundamental para a atuação do eu livre, um vez que aqui são gestados os projetos, antes de lançá-los ao mundo. 
O espaço íntimo não pressupõe transformação, mas é difícil concebê-la sem tal possibilidade.

A nascente distinção entre modalidades, assentadas em equilíbrio dialético, pode ser reproduzida na temporalidade. Dentro da consciência "presentificada", a primeira medida seria a diferenciação entre as estases temporais, que podem assim voltar ao exercício de seus "atributos" naturais. Ao prover estabilidade, o passado pode "liberar" a consciência do excesso de corporeidade. Além disso, ressurge a possibilidade biográfica, contraponto às "des-diferenciações" do endógeno, não apenas como entendimento compreensivo estático, mas como potência para a prospecção, afastando o indivíduo dos mais puros "experimentos da natureza". E, passado e presente, devidamente articulados, são fundamentais para a verdadeira transcendência.

Com a retomada de alguma prospecção, inicia-se um processo de ganho de diferenciação. Começam a despontar novos conteúdos, em oposição ao projeto psicótico, que destrói nuances e particularidades, nivelando a consciência aquém das possibilidades temáticas e de atuação no mundo. A procissão de novos conteúdos é motor de tração no sentido da ampliação da capacidade estrutural e reflexo de sua movimentação.

Na clínica, estas possibilidades podem se dar simultaneamente em uma variedade de fenômenos, como, por exemplo, o de oposição. De forma sumária, trata-se de uma relação de divergência, uma composição de forças de tendências contrárias. O conteúdo desta disputa não é o ponto de interesse aqui. As variações temáticas seriam eventos de segunda ordem e, mais que discorrer sobre a legitimidade da demanda do paciente, deve-se buscar o contexto formal para compreender o surgimento desse fenômeno dentro do curso clínico.

Estas manifestações não são atípicas no cotidiano psiquiátrico e ocorrem em uma ampla variedade de condições psicopatológicas (exemplo corriqueiro seria o da relação com pacientes borderline). Na clínica da esquizofrenia, é uma manifestação bastante heterogênea. Há ocorrências sistemáticas de oposição, de caráter generalizado, automático, que guardam relações de parentesco com o negativismo ativo. $O$ paciente se comporta de maneira opositiva, mas parece $o$ fazer de forma estereotipada, não havendo qualquer especificidade na eleição temática ou do opositor. A disputa não se sustenta, seja pela escolha de conteúdos irrelevantes, esgotáveis, seja pelo modo frouxo de ancoragem no outro. Tende a ser uma divergência estéril, um ato em "curto-circuito", do rol de expressões do 
autismo, distante de uma tentativa genuína de rearranjo estrutural, e mais próxima do pseudomovimento.

Em virtude da solidez inerente ao fenômeno, a oposição também pode atuar na acomodação estrutural. Inicialmente, provém estabilidade à estrutura que desfalece para depois se converter em rascunho de escape da emboscada psicótica. Este ensaio no sentido de uma efetiva transformação acontece em razão de diversos aspectos. A consciência em báscula encontra um ponto fixo na interpessoalidade. Emerge, assim, uma equação de distinção entre o eu e o outro/mundo, ajudando na superação da "exterioridade radical" da psicose. Há um acréscimo de possibilidades no rol das significações do mundo (é só contrastar com a hegemonia típica das convicções delirantes, por exemplo) e um decréscimo na materialidade (vide a rigidez das experiências delirantes ou ainda da corporeidade catatônica), ambas mais condizentes com a mobilidade. Com a oposição, surge algum relevo na planície autista e o paciente começa a frequentar o mundo através do opositor, um outro que é móvel, vivente e imprevisível.

Do ponto de vista da temporalidade, este fenômeno comporta algum vigor de abertura, não apenas pelo fato de estar assentado na interpessoalidade, mas também pela multiplicação de significações. Mesmo que não seja corriqueiro deparar-se com o terreno fértil das dúvidas, da indeterminação, a condensação típica da oposição oferece uma experiência de entrada no psiquismo alheio e de diferenciação. O surgimento de fenômenos de oposição altera a tonalidade afetiva e adentra-se em um momento de maiores incertezas e delicadezas na condução do caso em questão.

O caráter heterogêneo do fenômeno em relação ao todo da fratura psicótica autoriza certo otimismo e tal discernimento é capital para não correr o risco de aniquilar zonas "benignas". Essas devem ser protegidas no contato interpessoal, por exemplo, sob a forma de sustentação firme, provendo o suporte necessário, mas também propiciando condições crescentes de autonomia. $\mathrm{O}$ alongamento dos fenômenos de oposição pode favorecer o caráter fecundo destas manifestações, colocando o psiquismo em marcha e dando espaço para a emergência de projetos mais diferenciados.

Messas bem ilustra este fenômeno:

Queixar-se contra alguém é opor-se frontalmente a este alguém, é objetar seu movimento por uma resistência no sentido oposto. Neste braço de ferro existencial, o ser de menor força troca a sua posição de insuficiência por uma outra que, embora sem abandonar o perfil de 
inferioridade, coloca-a a serviço de uma redução de potência do outro. Postas frente a frente, duas consciências mesmo dotadas de poderes desiguais, tendem a se imobilizar temporariamente, num choque quase corporal. $\mathrm{O}$ jogo de forças contido no estado de oposição faz com que a consciência de menor força experimente um acréscimo de consistência existencial que mimetiza a inevitável corporeidade necessária para escapar ao colapso psicótico. Por outro lado, mantém ao mesmo tempo a relação dual em seu ponto máximo de valência e vigor. (Messas, 2010, p. 123).

Como regra geral em relação às tentativas de saída da psicose, pode-se dizer que o simples aparecimento de uma tendência oposta à vigente significa um ensaio de modificação formal. Após a acomodação da estrutura e a consolidação do sítio fundamental do processo patológico, antagonismos são benvindos. Nestes moldes, se estamos diante de uma consciência traduzida pela corporeidade, o aparecimento de pontos de "fluidez" (qualquer instância imaterial) pode animar o cenário. No caso contrário, de predomínio da leveza do imaginário, o surgimento de experiências mais materiais pode prover a ancoragem necessária para sair do colapso vigente. Mais fascinante ainda é o fato de que antídotos podem se tornar venenos, e vice-versa, mesmo em um único caso clínico. Vide a evolução de Ellen West, na qual a tendência a tornar-se "etérea" (a existência), alteração fundamental e dominante no início, ao ser substituída pela força de tração do mundo da "tumba", poderia funcionar como resistência ao processo patológico nesta fase final (Binswanger, 1968).

E, por fim, é evidente que, na patologia, domínio das leis e formas da natureza, movimentos de autodeterminação, típicos do núcleo do "eu livre", são a grande aposta de higidez. A constatação de um litígio entre as determinações endógenas e a decisão individual pode ser de grande alento, ainda que muitas vezes a estrutura não terá elasticidade suficiente para comportar tais distensões. Como já foi advertido por Binswanger, "a liberdade continua a serviço do homem, mesmo em situações extremas" (Binswanger, 1968, p. 372). A consciência, no exercício da decisão, composta por vontade, valores, entre outros, pode alterar o rumo da trajetória existencial. Quando isto ocorre, estamos distantes da determinação típica da patologia. 


\section{Algumas observações finais sobre cinética e terapêutica}

Ainda é preciso situar o papel da terapêutica em face das considerações cinéticas apresentadas. Apesar da enorme dificuldade de postular causalidades no âmbito mental, parece razoável discriminar distintos papéis para os investimentos farmacológicos na esquizofrenia. A medicação ora pode contribuir no sentido da paralisação necessária (por exemplo, nas fases de grande atuação endógena), ora pode ser importante para a mobilidade estrutural.

Os antipsicóticos não parecem capazes de mudar definitivamente a natureza, mas sim de exercer algum efeito de titulação sobre ela. Quando há alguma deflexão endógena, esta se dá através da lise ou diminuição das alterações típicas da fase de grande atuação endógena. Ou seja, a farmacologia é importante na contenção da potência endógena, o que abriria espaço para a reorganização no âmbito estrutural. "A ação neuroléptica pode objetivar uma imobilização de conteúdos, protegendo o todo psíquico de uma autoflagelação involuntária" (Messas, 2004, p. 157). Os momentos de grande atuação endógena requerem, em geral, uma atuação farmacológica mais incisiva, no intuito de minimizar a exposição da estrutura a uma força desenfreada.

Os antipsicóticos mimetizam algumas das soluções encontradas pela estrutura na fase de adaptação. A prescrição pode contribuir para a necessidade inicial de imobilidade, como, por exemplo, ao aumentar a preponderância da corporeidade ou ao "encistar" a consciência, limitando o horizonte vivencial. Assim, o manejo de efeitos "colaterais", como a apatia ou queixas somáticas, deve ser cauteloso, na medida em que eles podem ser mais terapêuticos do que parecem à primeira vista.

Uma vez obtida a acomodação estrutural, o desafio é o oposto: gerar movimentos em um contexto de hiper-estabilidade. Os antipsicóticos e outros psicofármacos também podem atuar na promoção dos desequilíbrios necessários à transformação.

Assim, mais que uma análise isolada de droga, deve-se ponderar o contexto psicopatológico para balizar as expectativas terapêuticas. Trata-se de uma situação dinâmica, que dificulta ambições causais definitivas. Congruente com esta afirmação é a frequente perda de efeito de uma medicação, ou seja, mesmo na vigência de tratamento adequado, a natureza pode ser convocada a atuar nova e incisivamente sobre a configuração temporoespacial. 
Em relação ao âmbito estrutural, a farmacologia não atua primordialmente aqui. Trata-se do território estratégico da psicoterapia. Entretanto, um projeto de psicoterapia parece só fazer sentido quando há o restabelecimento mínimo das condições estruturais para que ocorra interpessoalidade. Assim, quanto mais próximos dos "experimentos da natureza", mais distantes de um verdadeiro ensaio psicoterápico. De qualquer modo, uma "boa" psicoterapia na esquizofrenia pressupõe o reconhecimento claro das formas típicas da natureza e das soluções encontradas pela estrutura, além das condições técnicas e das particularidades vigentes, como o manejo constante de assimetrias.

É fundamental assinalar os riscos inerentes ao movimento da estrutura psicótica, possivelmente sendo o maior deles justamente o "despertar" do endógeno. Como já foi dito, qualquer nova possibilidade pode estar em campo minado. De qualquer modo, o contato interpessoal é sempre uma ferramenta fundamental para a condução clínica destes pacientes. Desde o manejo farmacológico até a detecção de configurações estruturais distintas e a de projeções de crescimento autênticos. E, sempre que possível, através da oferta de condições mais favoráveis para o seu florescimento das legítimas possibilidades individuais.

\section{Referências bibliográficas}

Biswanger, L. (1968). El caso Ellen West: estúdio antropológico-clínico. In: Existencia. Nueva Diménsion en Psiquiatria y Psicología. Madrid: Editorial Gredos.

Blakenburg, W. (1982). A dialectical conception of anthropological proportions. In: De Koonig, A. Jenner, F., editors. Phenomenology and Psychiatry (pp. 35-50). London: Academic Press.

Charbonneau, G. (2010). Introduction à la Psychopathologie phénoménologique. Paris: MJM Fédition.

Dörr Zegers, O. (1995). Psiquiatría Antropológica: contribuciones a una psiquiatría de orientación fenomenológica-antropológica. Santiago de Chile: Universitária.

Jaspers, K. (1997). General Psychopathology. Baltimore: The Johns Hopkins University Press.

Messas, G. P. (2004). Psicopatologia e Transformação: um esboço fenômeno-estrutural. São Paulo: Casa do Psicólogo. 
. (2010). Ensaio sobre a estrutura vivida. São Paulo: Roca.

Monkowski, E. (2000). La Esquizofrenia: psicopatologia de los esquizóides y los esquizofrénicos. México, D. F.: Fondo de Cultura Económica.

(2005). Le temps vécu. Études Phénoménologiques et Psychopathologiques. Paris, PUF.

Tatossian, A. (2006). A Fenomenologia das Psicoses. São Paulo: Escuta.

Tellenbach, H. (1975). La Melancolia. Visión histórica del problema: tipologia, patogenia y clinica. Madrid, Ed. Morata. 